(a)

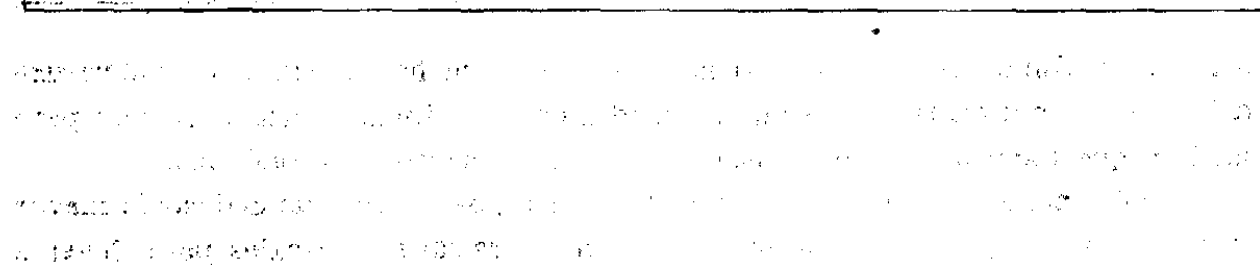

\title{
CALEIDOSCOPIO DEL TERCER MUNDO (1)
}

Con la expresión "países menos desarrollađos" se designa a casi 100 países, pobres en ingresos monetarios, pero diferentes en cuanto a cultura, situación económica y estructura social y política. La primera consecuencia de una preocupación por su desarrollo es reconocer esta inmensa diversidad. Por ejemplo:

Entre los paises de bajos ingresos se cuentan la India, con 530 millones de habitantes; Corea del Sur, con 30 millones; Costa Rica, con 1,5 millones, y el Gabón, con 500.000 . La India es una lederación đe diecisiete estados, él mayor de ellos con más rabitantes que cualquier país de Europa; el Gabón, por su parte, terene menos habitantes que un barrio de Londres. El gran tamafio comporta complejos problemas đe administración y cohesión política, pero también significa el disponér de grandes mercados y la posibilidad de economias en una escala correspondlenté. Los países pequefios suelen presentar un panorama bastante distinto, con problemas centrados en la exigliediad de sus entradas, la escasez de mano de obra destra y de profesionales y la debilidad de su posición en los mercados muitiales

Aunque la población crece rápidamente en la mayoría de los palsés en desarrollo; hay grandes diferencias en los problemas sociales y economicos cuando se trata de paises con $\mathbf{4 0 0}$ habitantes por kilómetro cuadrado, como el Pakistán orilental, y palses con una densidad de 10 habitantes por kilómetro cuadrado, como el Brasil. Cuando es posible abrir nuevas tierras al cultivo, sea cual sea el costo, th sicoófogia es distinta de cuando la superficie cultivable es fija y se stubdivide ể parcelas cace vez menos adecuadas.

Los sistemas políticos de los paises en desarrollo van desde fa democracta con plena participación, pasando por los sistemas de partido único, hasta las dictaduras. Algunas económias dependen espectalmente del sector pitvado y otras tei socto putblico; is mayoria de ellas se encuentra entre ambos extremós, salvo en lo que respecta a las empresas de servicios públicos y la industria pesada que, port lo común, son propiedad dèl Estado.

Al intenisiffcarse la conciencla política y diversificarse el poder económico, los valores tradicionales ceden ante nuevas modalidades de compartimiento quie se reflejan en una gama aún más rica de estructuras políticas y de politićas económicas.

"L tiversidad entre los sistemas de valores en los países de bajos ingrésos es, cứndo menos, tan grande como en el mundo industrializado. Algunas sociedades

(1) "De el Correo de la Unesco" Febrero 1970. 
son viejas, como las de México o la Indla; otras 20 ban lborada solontrinam

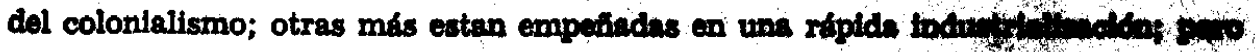
las hay que todavia no ban delineado una clare trajectorta 000 , the

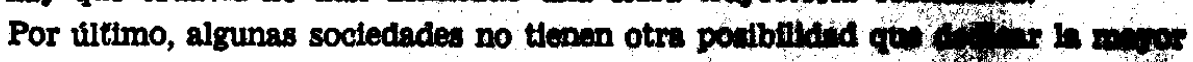

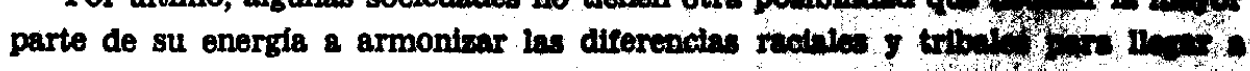

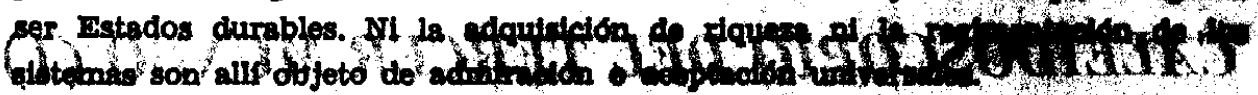

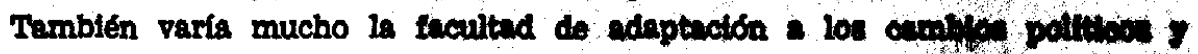

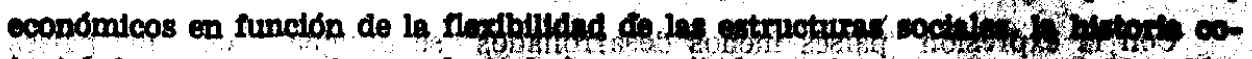



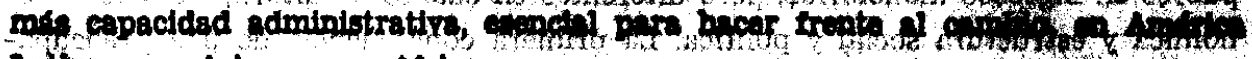
Lating $y$ en Asia que on Afrce.

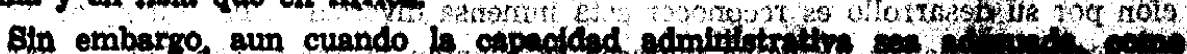
curre on el continente asiotion

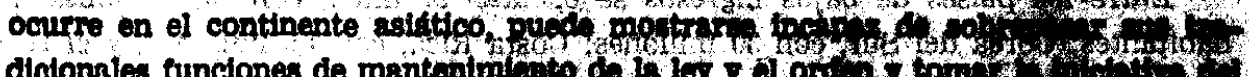

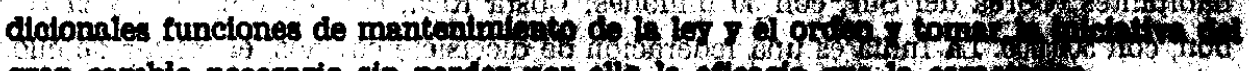



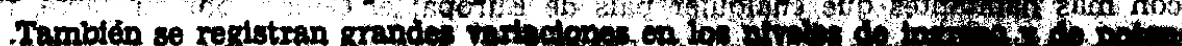
a 1 mono



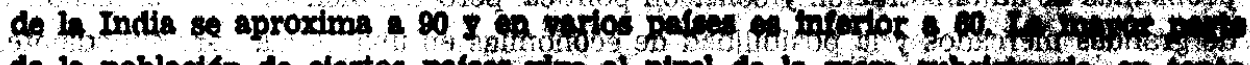

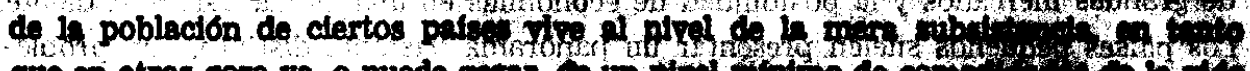

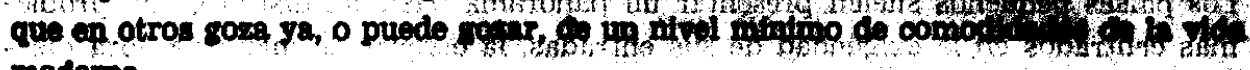
moderna.

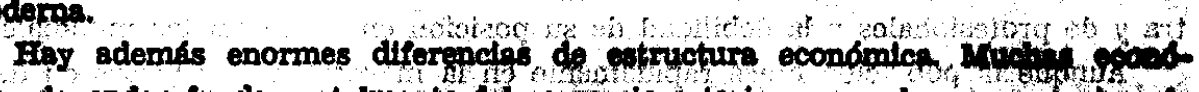

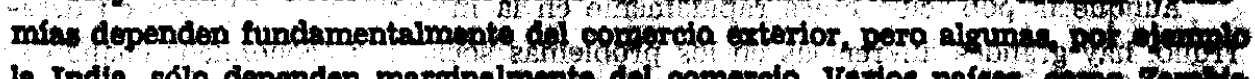

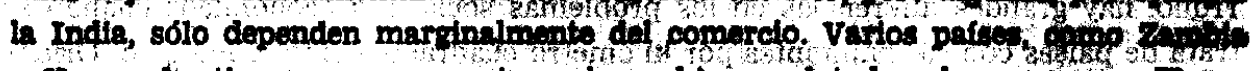

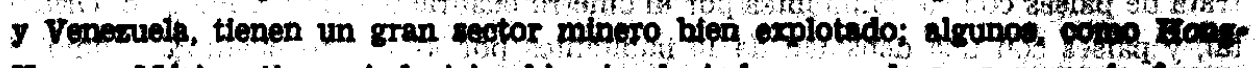

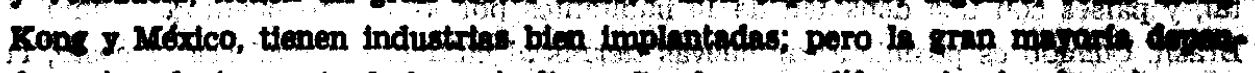

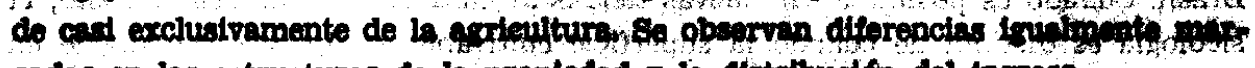

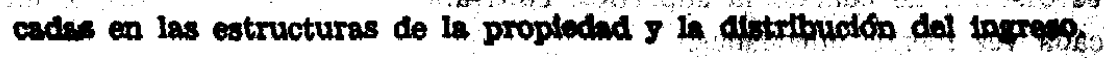

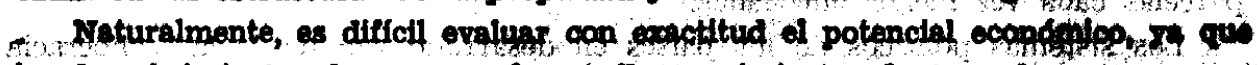



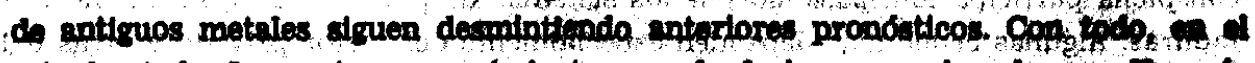



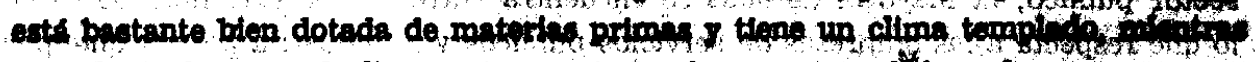

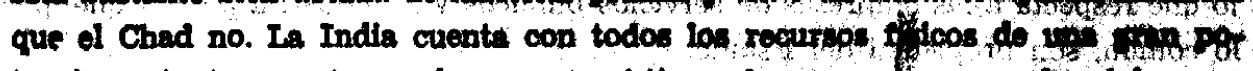

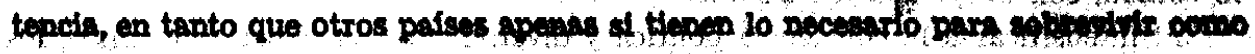
raclones.

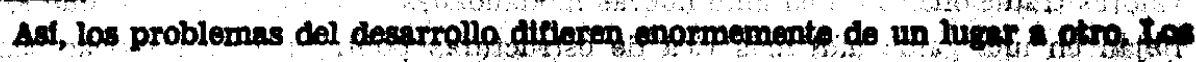
objotivos nacionales vienen doterminados por la experiencia y por la hifforth git-

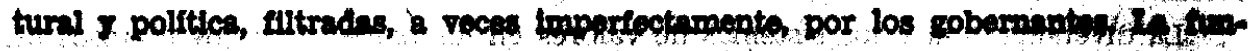

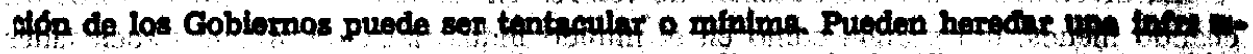
tructura y una capacidad adminiatrative amplias 0 indenificantos on on

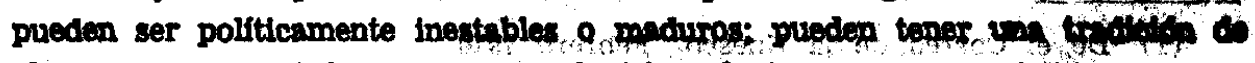
ahorro y laboriosidad, o tener que adquirir todsifa estas caracterinticis. 


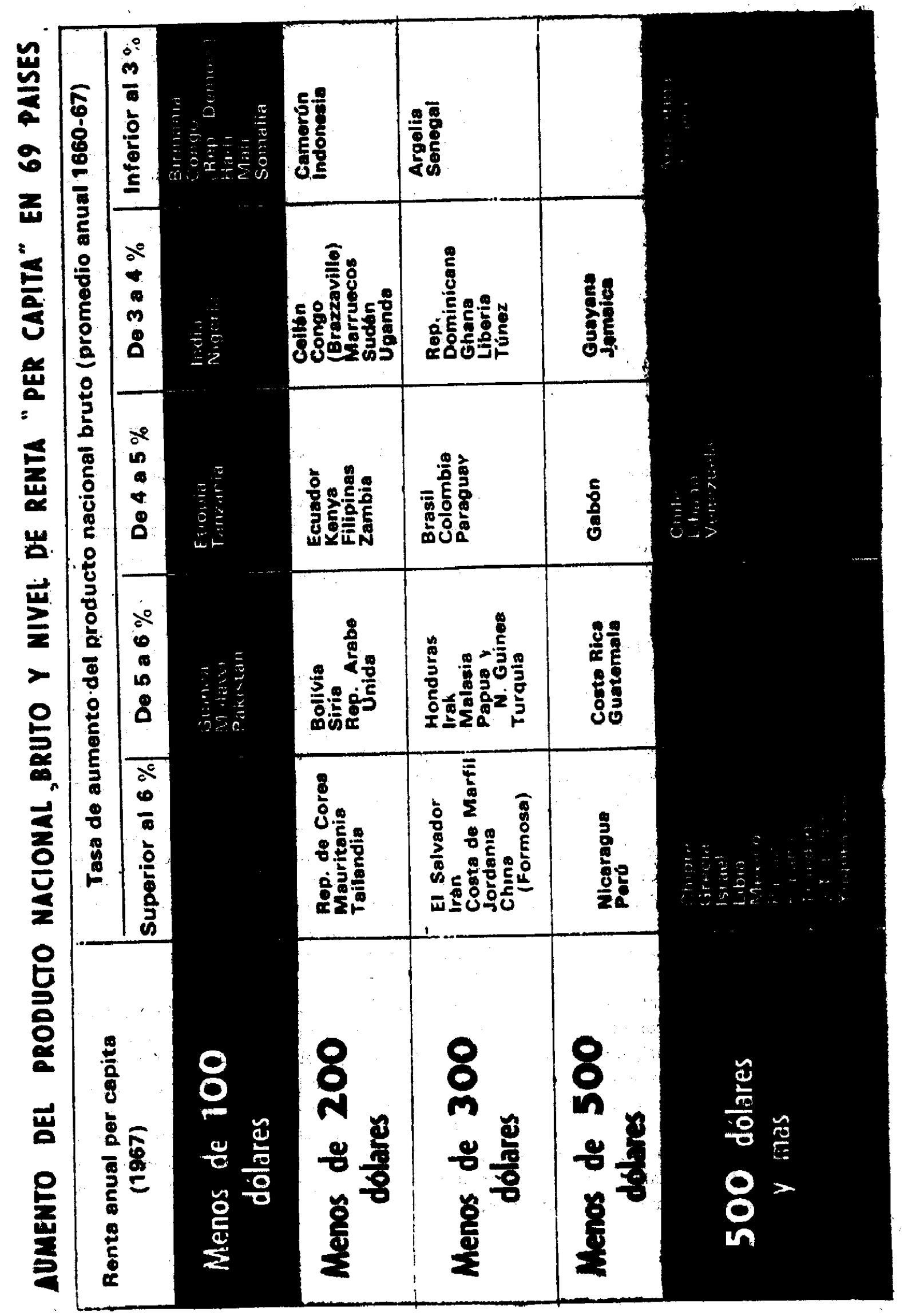




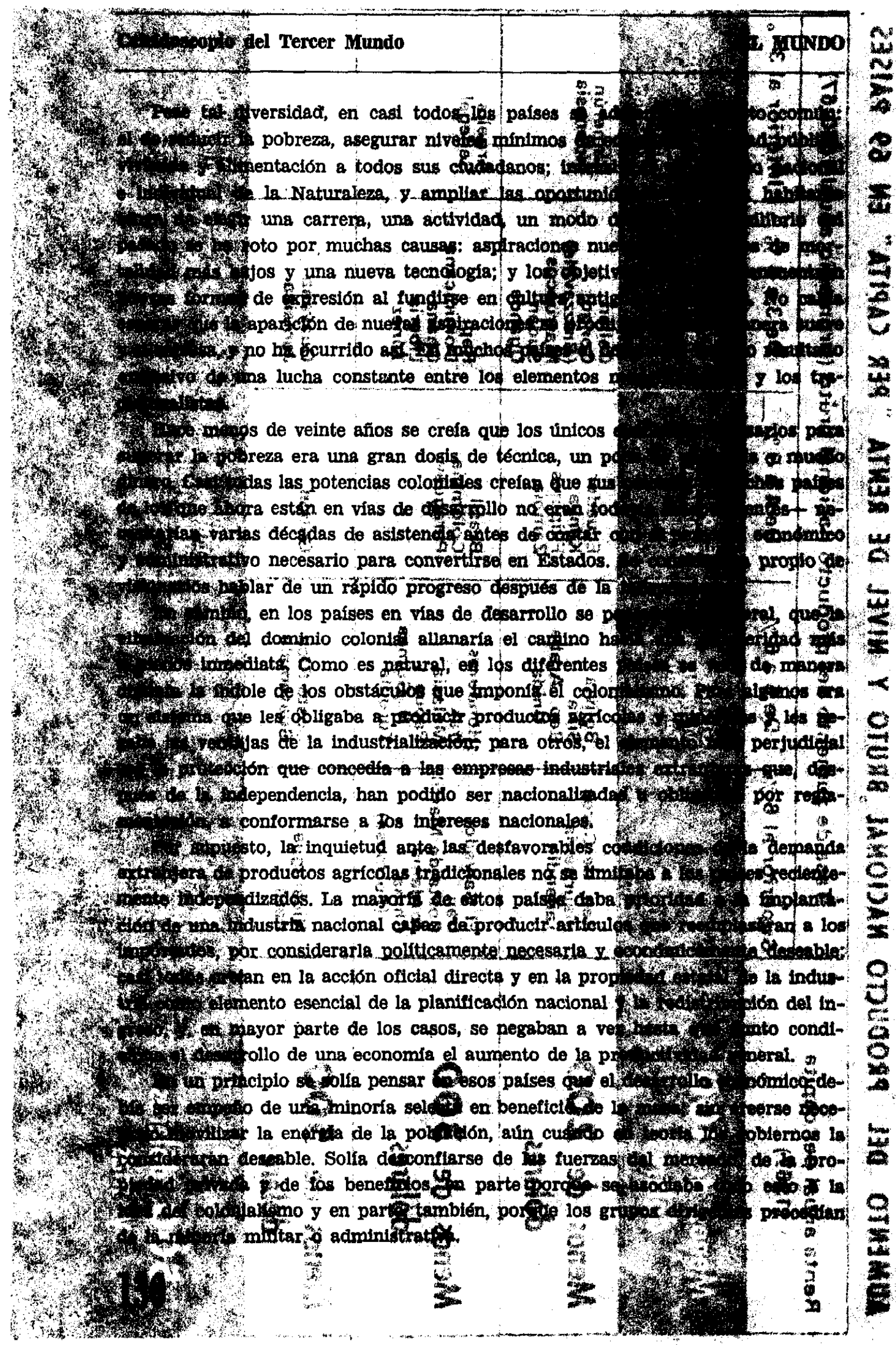


Los encargados de distribuir el ingreso de manera más equitativa desconoctan totalmente la manera de utilizar la legislación fiscal; los gastos publicos $\mathrm{g}$ tos incentivos generales como instrumentos de politica. Con frecuencta se interpretaba mal la función del Cobilerno on el fomento del desarrollo. Especialinente en tas antiguas zonas coloniales se veía al Gobierno como una continuactón det domfino colonial centralizado intervencionista.

Eran pocos los que comprendian bien la necesidad de recursos humanos patiz el rápido crecimiento economico, los que sentian hasta qué punto aumeritaba la demainds de servictos sociales, en especial en los centros urbanos, y los que se daban cuenta de la importancia de perfeccionar y ampliar la educactón y mejóta los servicios sanitarios.

Los paises donantes no daban pruebas de comprender mejor estos problemes. Les antiguas potencias coloniales continusron prestando astistencia flnanciera técnica a los. Fstados rectentemente Independizados, que tambien comenzarón a recibir ciertas asistenctio de otros donantes, pero el desarrollo no pasó a ser el eje de la aststencia sina lumgo de 1955.

In un principio se ereyó que bastaba con dar a esos pafses una aststeneta tet: nica basada en el envio de experto y la implantación de sistemas nuevos, asf como de medias financieros justificados por las condiciones comereiales; si bien podtin obtenerse préstamos en condiciones favorables, o donaciones-por ejemplo de los Zestados Onidos- poco ne sabia de la escala del problema que se trataba de resolver, de la magnitud del cambio social y politico necesario o del tiempo que extrafiaria logrario. Tampoco se prestaba gran atención a las repercustones as it politins comerclal o da las condiciones en que se otorgaba ta telistioncla.

Ia comprensión del desarrollo y de su efecto en toda la economia y la soctedtid he ido afinindose gradualmente, pero hasta nuestro decento este entendimiento más perfecto no se ha traducido en una decisión de prineiplo. El proceso disto todovia de haber tocedo a su fin.

- Simplificariones tan extremas como éstas llevaron a los paises industrialé - los de bajos ingresos a insistir demactado en las corrientes de astistioncta y ex el erecimiento del producto nacional bruto por capita, hibito que sollo va cectiend'b lugar con lentitud a la tedea de que el efecto de las corrientes as arras sobxe of proclacto nacional bruto depende en buens parte de la eftieionola cen que el quats receptor utiliza sus recursos internos y aplica sus politicas ecorondicas y soctidiof.

Ihstas politicas tienen otros objetivos - por ejemplo, la igualdied en la ditit

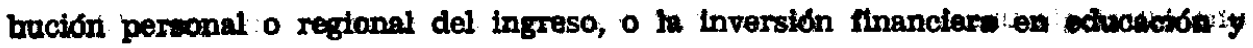
servicios socinies- que; a veces, no han de alcanzarse sino haclendo mis twites el ritmo de desarrollo. También se comprende ahora mejor are he corrientes sole asistencia pueden legar a ser contrarrestadas, 0 el crecimiento verse umilado, por el mail functonamiento del intercambio comercial o por poltuces movetiutas mal schotadials.

Ins emfoques del pasado se van modificando de modo graduil con ts oxpentens

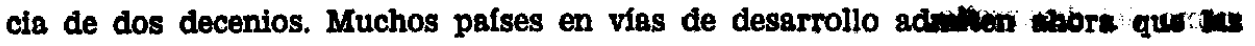






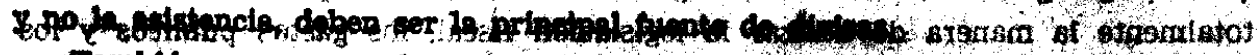

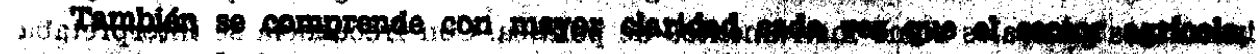

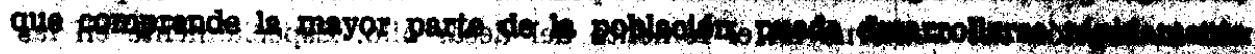

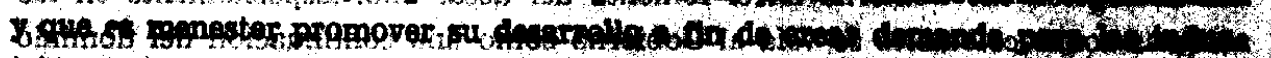

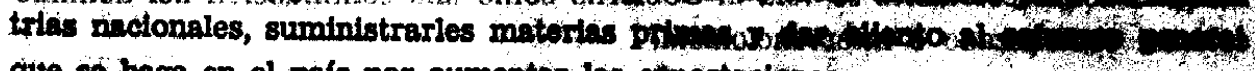

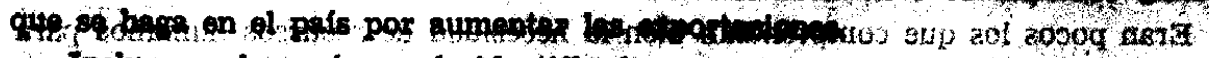

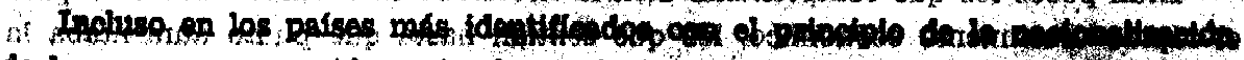

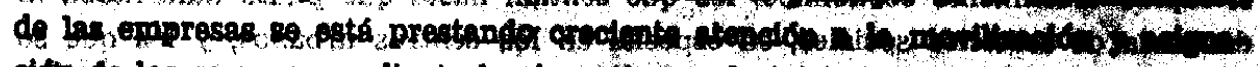

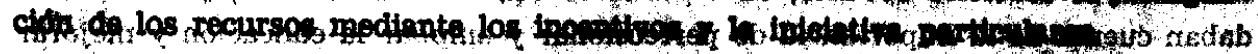

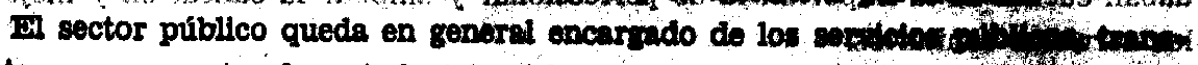

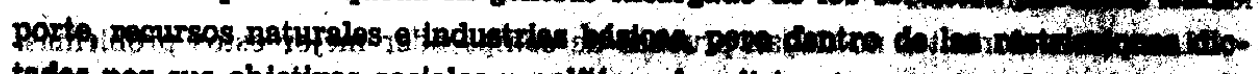

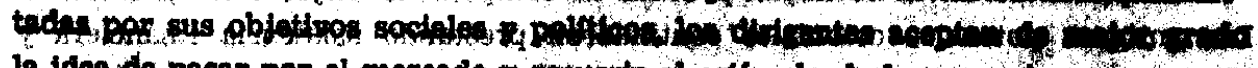

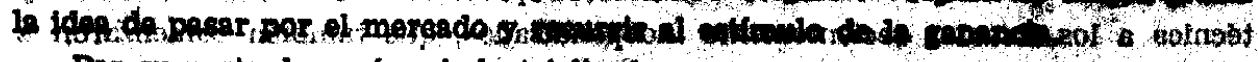

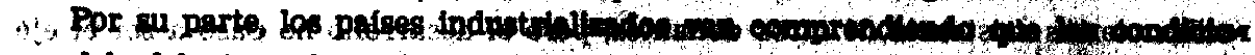

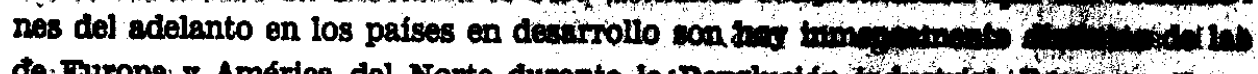

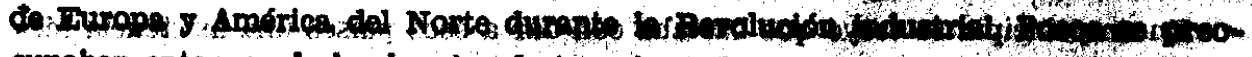

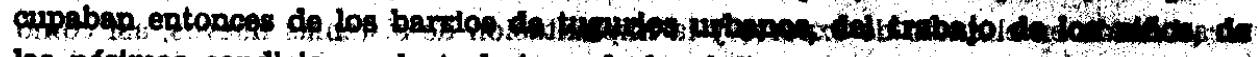

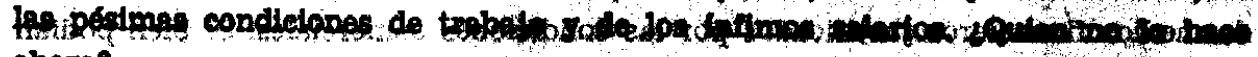
hpras.

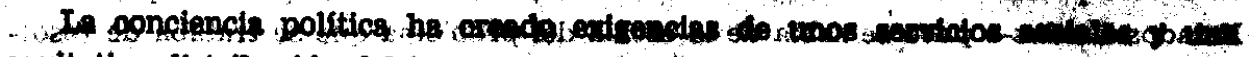

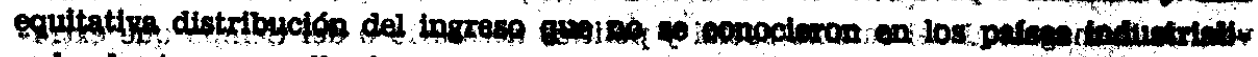

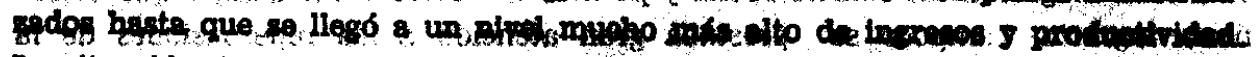

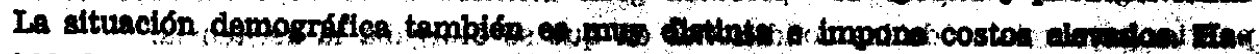

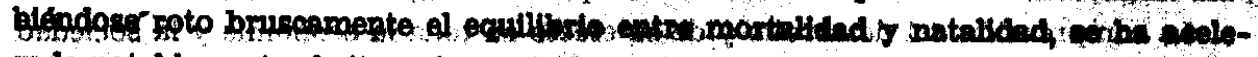

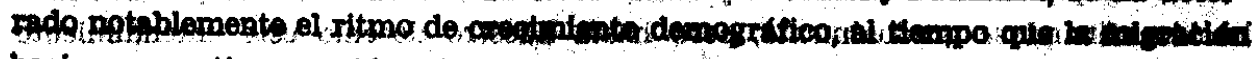

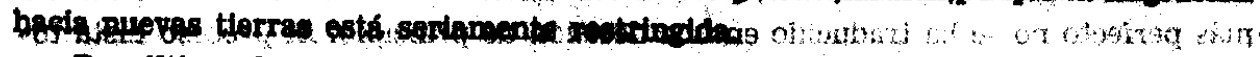

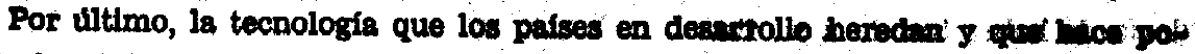

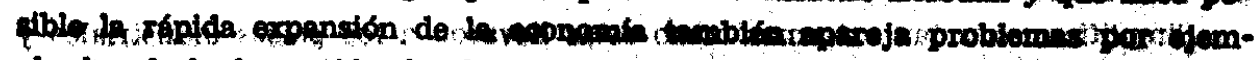

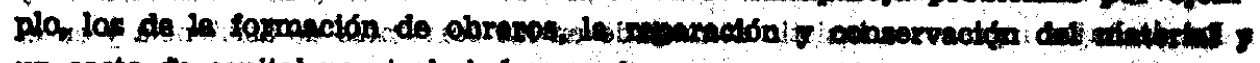

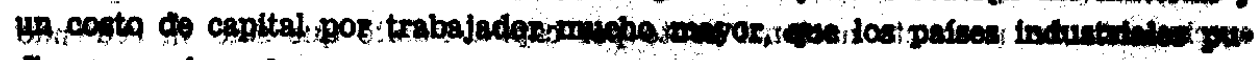

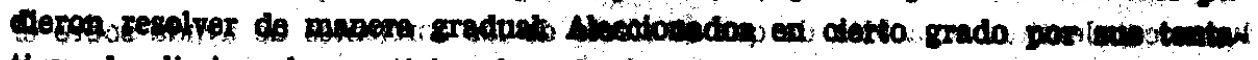

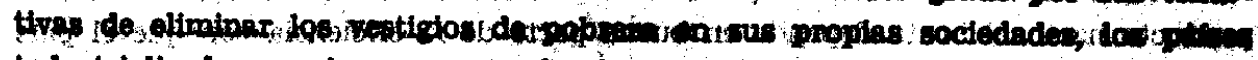

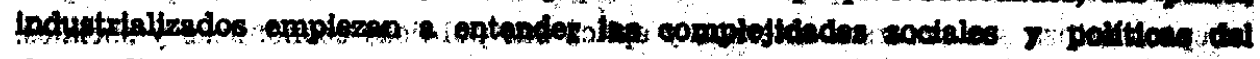

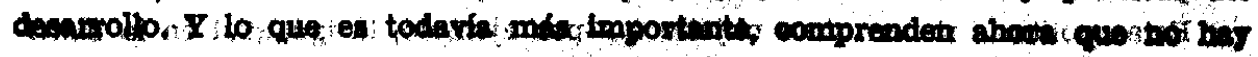

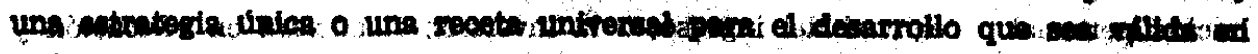

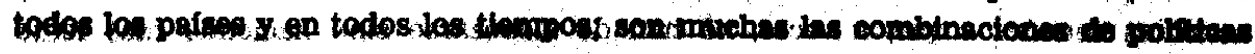

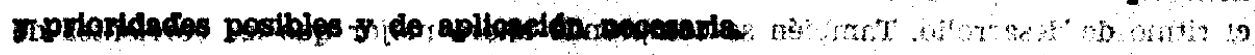



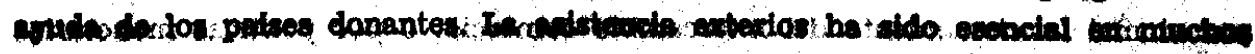

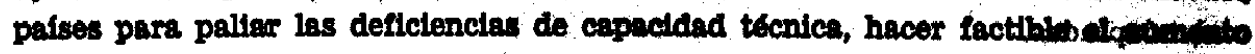

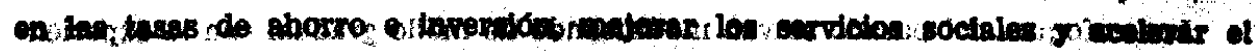

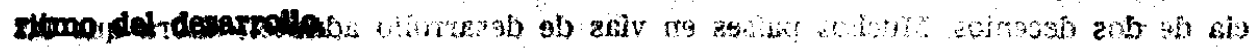

199. 
Pero la asistencia también ha contribuido a lograr otros progresos de importancia fundamental. Cuando se la ha prestado de manera adecuada, ha dado a los paises de bajo ingreso la necesaria nexibilidad para emprender camblos tan audaces de politica como la devaluación y la liberalización de las restricciones a la importación. (Lógicamente, la circunstancia de que la ayuda no haya aumentado on los últimos años ha hecho más y más difficil movilizar el apoyo suficiente como para lograr cambios de política transcendentales en los países en que la escasez de divisas ha sido la restricción primordial para el desarrollo).

En el Africa, pese a que las divisas en moneda extranjera no son todaria la principal restricción, el volumen de ayuda y la relación existente en este sontido entre país donante y pais beneficiario desempeñan una importante función en la formulación de la polftica económica.

sun en los casos en que se ha reconocido la importancia de los estuerzos y las políticas de los pafses beneficiarios, el diálogo entre donantes y recipientes ha solido ser insatisfactorio. A veces el análisis concertado de un problema ha culminado en una acción eficaz por ambas partes, pero en muchos casos falta el esfuerzo verdadero por desarrollar la economía de un lado 0 de otro, 0 de ambas partes, o si no, se lo interpreta mal.

Estos problemas comprenden desde la renuncia de los paises beneficiarios a hacer frente a los intereses creados hasta la negativa del donante a prestar asistencia a sectores potencialmente competitivos o a abrir sus mercados a productos nuevos. El país donante y el país receptor también difieren trecuentemente en sus opiniones sobre la trascendencia o las consecuencias politicas de una medida, 0 sobre la celeridad con que puede ponerse ex práctica

Por último, las prioridades políticas de ambas categorias de paises suelen ser Indefinidas $\mathrm{y}$, ciertamente, variables. Los paises receptores han recibido consejos contradictorios por parte de distintos donantes, o de una misma institución en épocas diferentes. Sus prioridades se ven sometidas y a las presiones politicas normales, $y$ el orden y aplicación de las mismas les son dificiles.

Asf, aunque la atención se haya centrado con éxito en las politicas de desarro$110 \mathrm{y}$ en el apoyo que requieren, el mecanismo de aplicación de los resultados de un analisis hecho en común dista, con notables excepciones, de ser adecuado a los tines que se persigue. 